\section{OPEN ACCESS}

Edited by:

João Eurico Fonseca,

Universidade de Lisboa, Portugal

Reviewed by:

Mihir D. Wechalekar

Flinders Medical Centre, Australia

vasco C. Romão,

University of Lisbon, Portugal

*Correspondence:

Laurent Meric De Bellefon

laurent.meric@uclouvain.be

Specialty section: This article was submitted to Rheumatology,

a section of the journal

Frontiers in Medicine

Received: 07 November 2018

Accepted: 02 January 2019

Published: 22 January 2019

Citation:

Meric De Bellefon L and Lazarou I (2019) US-Guided Biopsies:

Overarching Principles.

Front. Med. 6:1

doi: 10.3389/fmed.2019.00001

\title{
US-Guided Biopsies: Overarching Principles
}

\author{
Laurent Meric De Bellefon ${ }^{1,2 *}$ and llias Lazarou ${ }^{3}$ \\ ${ }^{1}$ Cliniques Universitaires Saint-Luc, Brussels, Belgium, ${ }^{2}$ CHU Saint-Pierre, Brussels, Belgium, ${ }^{3}$ Department of \\ Rheumatology, Université de Genève, Geneva, Switzerland
}

Gathering synovial tissue from any swollen joint especially in early arthritis patients is critical for good quality research and to obtain further insight into the pathophysiology of inflammatory joint diseases. Multiplying biopsy sites is a challenge in terms of the techniques needed for each different joint but also in terms of safety and tolerability. It is important to provide the best care especially in very early arthritis patients who have only had the disease for a few months. This review discusses the minimal requirements applying to antiseptic techniques for the operator's hands, patient preparation, local anesthesia, and post-procedure care.

Keywords: synovial biopsy, anesthesia-local, arthritis (including rheumatoid arthritis), antisepsis, ultrasound guided biopsy techniques, local anesthesia

\section{INTRODUCTION}

Synovial biopsy with ultrasound guided techniques is a safe and well-tolerated procedure however it remains invasive. As such, rheumatologists have to follow some basic aseptic techniques in order to avoid complications.

This review will first discuss the preparation of the patient and the operator, then local anesthetics, the possibility of corticosteroid injections, and post-procedure care.

\section{ASEPSIS FOR THE OPERATOR}

\section{Surgical Hand Antisepsis}

Preoperative cleansing of hands and forearms with an antiseptic agent has been an accepted practice since the late 1800s (1). Despite a large body of indirect evidence for the need of hand antisepsis prior to surgical interventions this has never been proved by randomized, controlled clinical trials.

United States of America (USA) guidelines recommend the use of agents for surgical hand scrubs which substantially reduce microorganisms on intact skin, contain a non-irritating antimicrobial preparation, have broad-spectrum activity, and are fast-acting and persistent $(2,3)$.

Reducing resident skin flora on the hands of the surgical team for the duration of a procedure reduces the risk of bacteria being released into the surgical field if gloves are punctured or torn during surgery (4-6).

The World Health Organization (WHO) has provided very precise definitions and has also described operator's hand antisepsis step by step (7-9). Surgical handscrubbing refers to the use of soap and water, while surgical handrubbing is the use of a waterless, alcohol-based solution. The alcohol-based (hand) rub is an alcohol-containing preparation (liquid, gel, or foam) designed to be applied to hands to kill microorganisms and/or temporarily suppress their growth. 


\section{Which Products Should be Used for Surgical Hand Preparation?}

There are slight differences in terms of requirements between USA and European guidelines. Guidelines in the USA recommend that agents used for surgical hand preparation should significantly reduce microorganisms on intact skin, contain a non-irritating antimicrobial preparation, have broadspectrum activity, and be fast-acting and persistent (10). In Europe, all products must have at least the same efficacy as a reference surgical rub using n-propanol, as outlined in the European Standard EN 12791. In contrast to the USA guidelines, only the immediate effect after the hand hygiene procedure and the level of regrowth after $3 \mathrm{~h}$ under gloved hands are measured. The cumulative effect over 5 days is not an EN 12791 requirement.

Surgical hand antisepsis can be achieved using medicated soap such avec chlorhexidine gluconate (CHG) $4 \%$ or povidone-iodine which both result in similar reductions of bacterial counts (70$80 \%)$. Despite both in vitro and in vivo studies demonstrating that povidone-iodine is less efficient than chlorhexidine, it remains one of the widely-used products for surgical hand antisepsis, although it induces more allergic reactions, and does not have similar residual effects $(11,12)$.

Surgical hand preparation with alcohol-based handrubs seems to be a safer method with a higher reduction of bacterial counts compared to other agents and a greater acceptability and fewer adverse effects on skin. Only alcohol-based hand gels which have passed the EN 12791 test or an equivalent standard for handrub formulations e.g., FDA TFM 1994, should be used (13). Such preparations usually contain $60-95 \%$ ethanol or isopropanol.

Both methods are suitable for the prevention of Surgical Site Infections (SSIs) but WHO panel experts have declared a preference for alcohol-based products.

\section{Key Steps Before Entering the Operating Theater}

Rings, wristbands and watches must be removed and nails must be short and clean without nail-polish. False nails should also be avoided.

Hands and forearms may be washed with non-medicated soap and water. This part is not necessary unless hands are visibly soiled or dirty but it is highly recommended to eliminate any risk of colonization with bacterial spores (14-16).

\section{Aseptic Procedure}

Here we describe the alcohol-based handrub (ABHR) according to $\mathrm{WHO}$ recommendations. Apart from a few cases of very large hands and forearms, $15 \mathrm{ml}$ of ABHR are usually enough for the whole procedure.

First, fingertips and forearms are cleaned using 5 millilitersor 3 doses of $\mathrm{ABHR}$ - for each side. This takes $\sim 1$ min with an emphasis on the forearms. Second, hands are then rubbed with $5 \mathrm{ml}$ of ABHR keeping the hands held higher than the elbows.

The whole handrub procedure lasts $1.5 \mathrm{~min}$ with the recommended ABHR formulations.
The operator's hands are then considered sterile and the operator can enter the procedure room and put on the sterile gloves ( 2 pairs) and gown.

\section{MATERIAL NEEDED AND TECHNIQUE}

\section{Table Preparation}

On a sterile drape, place sterile gauzes $(5 \times 5$ or $7.5 \times 5 \mathrm{~cm})$, sterile drapes (adhesive $75 \times 75$ or $140 \times 190$ non-adhesive), $10-$ 20 needles for biopsy collection, 1 sterile probe sheath, needles for local anesthetic (1 26-G for the skin, $120 \mathrm{G} 50 \mathrm{~mm}$ and $118 \mathrm{G}$ $50 \mathrm{~mm}$ ), syringes (20 $\mathrm{ml}$ for CHG, $10 \mathrm{ml}$ for lidocaine) (Figure 1). The disposable biopsy needle or the instruments portal \& forceps (18 G needle, wire, and dilators, optional metallic instruments, flexible, and/or rigid forceps) are also placed on the sterile drape. According to the antimicrobial agents chosen, $150 \mathrm{ml}$ of $\mathrm{CHG}$ or PVI-I are usually enough.

The sterile probe sheath may need to have non-sterile ultrasound gel poured inside it to maintain contact with the probe. Some probe sheaths have an adhesive area for the probe so that no gel is needed. As a contact medium between the sheath and skin, we prefer to use chlorhexidine gluconate $4 \%$ rather than a sterile gel. A volume of $20 \mathrm{ml}$ is usually sufficient for the whole procedure.

\section{Ultrasound-Guided Synovial Biopsy Techniques}

Ultrasound-guided synovial biopsies can be performed using two different techniques. One uses a portal and forceps (P\&F) where a modified Seldinger technique is used to position the coaxial sheath and also to provide a portal for irrigation. The biopsies are then performed with a flexible or rigid forceps under ultrasound guidance (17). The other technique uses a dedicated disposable semi-automatic guillotine-type biopsy needle (BN). It can be used with or without an introducer according to the size of the biopsied joint. Several disposable devices are available, e.g., Tru-Cut (UK Medical) or Quick-Core (Cook Medical), Temno Evolution (BD). There may be some differences found in needle

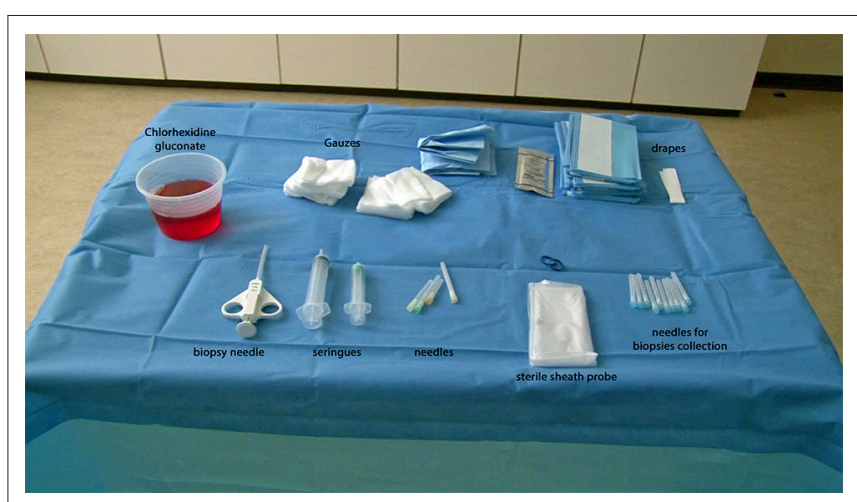

FIGURE 1 | Prepared table with the material needed for ultrasound-guided synovial needle biopsy. 
rigidity, the shape of needle bevel, the sensitivity of the semiautomatic mechanism trigger.

The USG biopsies performed either with $\mathrm{P} \& \mathrm{~F}$ or a disposable needle offer the same quality of histological analysis of the tissues and the same safety in terms of side effects. Tolerability of both is also good and comparable.

The main differences between these two techniques are that procedure duration is marginally higher for $\mathrm{P} \& \mathrm{~F}$, that $\mathrm{BN}$ uses disposable material compared to autoclavable equipment for $\mathrm{P} \& \mathrm{~F}$, and that $\mathrm{P} \& \mathrm{~F}$ often requires two operators (18).

\section{PATIENT PREPARATION}

\section{Patient Position and Procedure Room}

The patient may be sitting or lying comfortably on a bed according to the target joint. Comfort is particularly important for arthritic patients with active disease.

The patient has to remove rings and bracelets, and has to wear a mask. Shaving of the area where the needle is to be introduced is not required.

Enough space must be provided for the ultrasound machine on the side of the patient opposite the operator, and for the sterile gown to be put on with the aid of an assistant. A dedicated room for the procedure is recommended but any space fulfilling local patient safety standards may be used.

\section{Patient Asepsis}

The aim of this procedure is to reduce the microbial load on the patient's skin as much as possible before breaking the skin barrier.

In Europe, the antimicrobial agent recommended is chlorhexidine gluconate $4 \%$ (CHG) but povidone-iodine is also frequently used. In the USA, despite the fact that chlorhexidine gluconate is superior to povidone-iodine for patient preoperative skin preparation, it is still not eligible for that use because of different standards for efficacy.

CHG is a cationic bisbiguanide developed in England in the early 1950s. It is effective on Gram positive and negative bacteria and also against lipophilic viruses (Human Immunodeficiency Virus, influenza, herpes simplex). It has a persistent antimicrobial action that prevents regrowth of microorganisms for up to $6 \mathrm{~h}$. There is no evidence of CHG being toxic if it is absorbed through the skin. This point is crucial and explains why sterile gels are not essential as a contact medium during the ultrasound procedure, as they can be replaced by CHG. Finally, there is a low incidence of hypersensitivity reactions and skin irritation but one has to keep in mind that some severe allergic reactions have been reported (including anaphylaxis).

Povidone-iodine contains $9-12 \%$ available iodine and is eligible for patient antiseptic skin preparation, health care personnel hand washing and surgical hand scrubbing. Bacteria do not develop resistance to PVP-I (19).

The area to wash will obviously depend on the target joint:

- For the wrists, metacarpophalangeal (MCP), and proximal interphalangeal (PIP) joints: hand and forearm up to the elbow (Figures 2C,D).

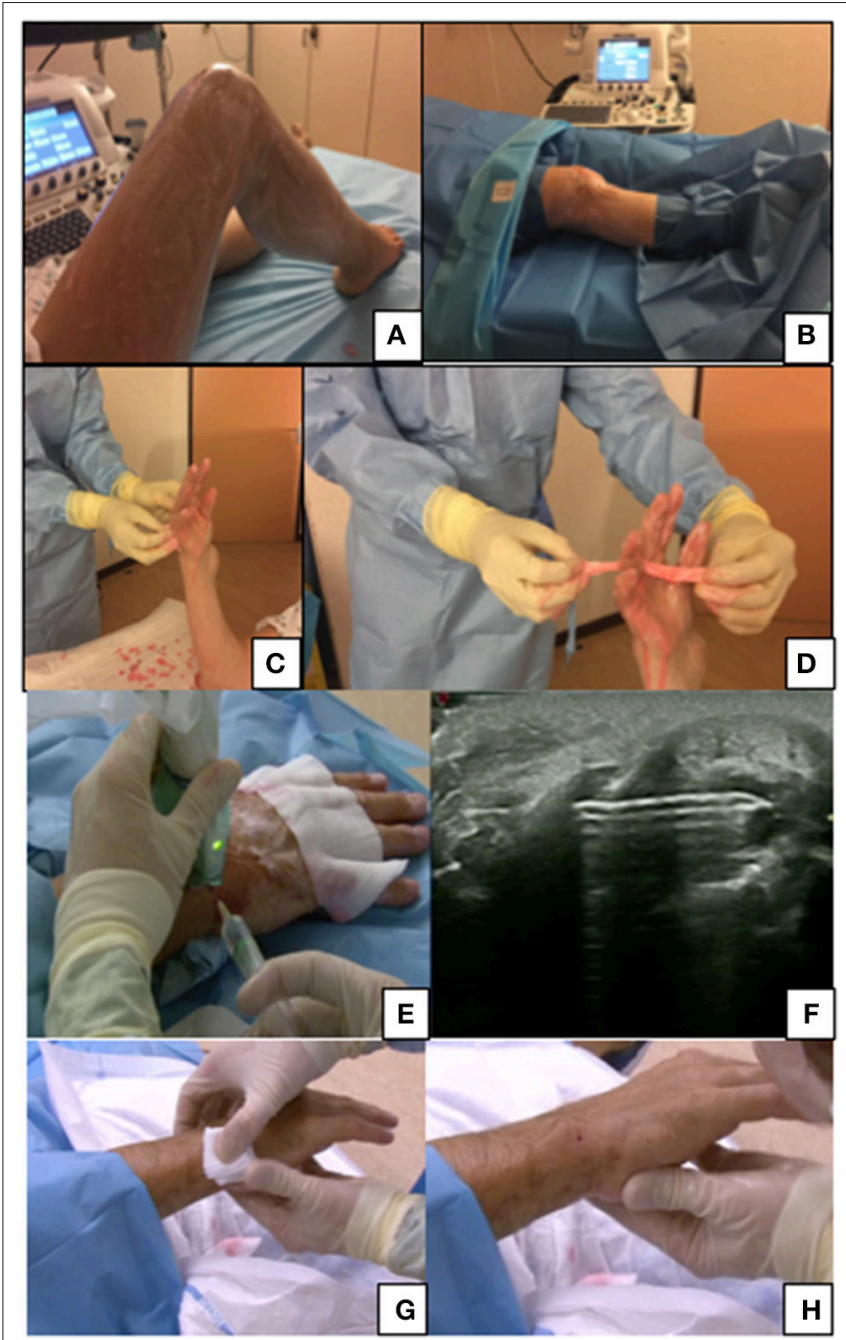

FIGURE 2 | (A,B) Preparation for knee biopsy, patient lying. (C,D) Hand washing before a biopsy of wrist/PIP with a focus on the interdigit region washing. (E,F) Articular anesthesia after skin anesthesia with 18G $50 \mathrm{~mm}$ needle under ultrasound guidance. (G,H) Post-procedure care, a 2 min compression of the hole entrance before putting a small dressing.

- For the elbow: most of the arm and forearm excluding the distal third of the forearm and proximal third of the arm

- For the knee; most of the thigh and the leg excluding the distal third of the leg and proximal third of the thigh (Figures 2A,B).

- For the ankles, metatarsophalangeal (MTP), and proximal interphalangeal (PIP) joints: the leg up to the knee, the ankle and foot.

The area of interest is washed with sterile compresses dipped in the chosen antimicrobial agent solution (CHG or PVP-I). A couple of rubbings of the area of interest are usually enough. For hands and feet, special care should be taken for the interdigital areas and nails. After disinfecting, sterile drapes should be placed to isolate the target joint.

The first pair of gloves (no longer considered sterile) should be discarded. 
The assistant (e.g., nurse) has to wear a mask and gloves. One member of the family may be present according to local policies, and they should also wear a mask.

\section{LOCAL ANESTHESIC}

Lidocaine $1 \%(\mathrm{w} / \mathrm{v})$ is recommended for the local anaesthesic (LA). The volume depends on the size of the target joint from $3 \mathrm{ml}$ for MCP and PIP to $10 \mathrm{ml}$ for big joints such as knees. The maximal dose is $4-5 \mathrm{mg} / \mathrm{kg}$. In adults, the average lidocaine injected dose is far below the maximal dose. For example, in a $60 \mathrm{~kg}$ patient, injection should not exceed $300 \mathrm{mg}$ of lidocaine, whereas $10 \mathrm{ml}$ of lidocaine $1 \%(10 \mathrm{mg} / \mathrm{ml})$ only correspond to $100 \mathrm{mg}$. Doses must be carefully calculated for children.

The LA is performed under ultrasound guidance with a suitable needle from the skin to the synovial hypertrophy and the anesthetic effect is usually very quick (1-3 min). Alternatively, a subcutaneous needle can be used for the skin followed by the deeper injection with a thicker needle (Figures 2E,F).

\section{Adverse Events}

Side effects-neurological and cardiovascular-are more common in cases of overdosing or intravascular injection. Patients may experience paraesthesia, a metallic taste, blurred vision, tinnitus, an increase in blood pressure or cardiac arrhythmias.

\section{Chondrotoxicity of Anesthetic Agents}

Severe cartilage damage has been reported with the use of local anesthetic but mainly with continuous intra-articular infusion with bupivacaine, the gleno-humeral joint being the most commonly affected. Thus far, there is no clinical evidence of chondrolysis resulting from a single injection of local anesthetic but rheumatologists have to be aware that ex-vivo studies have demonstrated that bupivacaine, lidocaine, ropivacaine, and levobupivacaine are toxic for cartilage. The mechanisms are still unknown, but mitochondrial DNA damage or chemical incompatibility have been suggested and there seems to be a doseand dose-over-time effect on toxicity $(20,21)$.

In animal models the assessment of in vitro chondrotoxicity showed a dose- and time-dependent effect of lidocaine on the viability of articular cells $(22,23)$.

\section{Antimicrobial Effect of Lidocaine}

Lidocaine like the other local anesthetic agents possesses bacteriostatic, bactericidal, fungistatic, and fungicidal properties. This role has been documented with in vitro and in vivo studies since 1950. The exact mode of action is not known but some believe that local anesthetics cause a disruption of microbial cell membrane permeability, leading to a leakage of cellular components and subsequent cell lysis. Lidocaine demonstrated a dose-dependent inhibition of growth for all strains of bacteria tested, with the most activity against gramnegative organisms, and the least against Staphylococcus aureus. The addition of epinephrine to the local anesthetic had no effect on the susceptibility of the bacteria to lidocaine.

Thus, on the one hand lidocaine is beneficial in preventing joint infections after invasive procedures, but on the other hand, it could lead to false-negative results or suboptimal culture yields for biopsies $(24,25)$.

\section{POST-PROCEDURE CARE}

Theoretically ultrasound guided synovial biopsy procedure may cause infection, bleeding, or lesions of tendons or nerves. This is why the ultrasound pre-biopsy assessment is important, with the identification of the vascular structures and the tendons in the joint of interest. The continuous visualization of the needle and its tip throughout the procedure is also important for the same reason. This is important for complex joint such as wrists, elbows, or ankles biopsies. In the event of unexpected bleeding, clinical examination, and surveillance is recommended.

The very good tolerability of the ultrasound guided synovial biopsy has been demonstrated in many studies and no intense pain should be expected at short- or long-term after biopsies (26).

In practice, once the procedure is finished, the entry site is gentle cleansed with sterile water. A small dressing is placed after 1-2 min of compression on the entry site where there should be a tiny red spot (Figures 2G,H). A bandage can be put around the biopsied joint but is not essential. The dressing and the bandage can be removed the next morning.

Contact details of the operator or department should be given to the patient in case of significant pain, swelling, bleeding, or neurologic symptoms during the week after the procedure.

\section{INTRA-ARTICULAR GLUCOCORTICOID (GC) INJECTIONS}

Methylprednisolone $40 \mathrm{mg} / \mathrm{ml}$, triamcinolone acetonide 40 $\mathrm{mg} / \mathrm{ml}$ or triamcinolone hexacetonide $20 \mathrm{mg} / \mathrm{ml}$ can be injected into the joint under ultrasound guidance of the at the end of the biopsy procedure if needed. A $50 \mathrm{~mm}$ long $20 \mathrm{G}$ needle is suitable for the injection. With the exception of large joints, some of the GC might leak from the needle entry site since pressure builds up during the procedure and LA injection.

In terms of safety, intra-articular glucocorticoid injections are safe with a low incidence of septic arthritis: $1 / 27.000$ in a Dutch retrospective study from 2008 and 2013 (27). In a retrospective multicentric study in patients undergoing synovial biopsies using different techniques (ultrasound-guided or arthroscopic-guided), Soeren et al. recently reported 38 intra-articular joint injections without any increase in adverse events including infections. They were also associated with a statistically significant reduction in post biopsy swelling (28).

\section{CONCLUSIONS}

Aseptic techniques for preoperative preparation of patient's skin may vary slightly according to your country or your hospital but their basis and definitions are precise and based on numerous studies. Every rheumatologist who starts performing synovial biopsies has to refresh or acquire knowledge in this specific domain. To date, precise, validated and easily accessible recommendations are published. USG biopsies either with $\mathrm{P} \& \mathrm{~F}$ of with a disposable needle biopsy require 
heeding these precautions. Chlorhexidine gluconate and povidone-iodine can be used for patient skin preparation while alcohol-based handrubs are used for surgical hand preparation.

One has to be aware of the maximal dose, side effects and potential chondrotoxicity of local anesthetics. Ultrasound prebiopsy examination is important so as to choose the joint of interest and to assess biopsy feasibility. Identification of the different structures (tendons, blood vessels, nerves) along the

\section{REFERENCES}

1. Gröschel DHM, Pruett TL. Chapter 36: Surgical antisepsis. In: Block SS, editor. Disinfection, Sterilization and Preservation. 4th ed. Philadelphia, PA: Lea and Febiger (1991).

2. Food and Drug Administration. Tentative Final Monograph for Healthcare Antiseptic Drug Products; Proposed Rule. Federal Register (1994). p. 31441-52. Available online at: https:/www.federalregister.gov/documents/2015/05/01/ 2015-10174/safety-and-effectiveness- of-health-care- antiseptics- topicalantimicrobial-drug-products-for

3. Fogg D, Parker N, Shevlin D, editors. Standards, Recommended Practices, and Guidelines. Denver, CO: AORN (2001).

4. Rotter M. Chapter 87: Hand washing and hand disinfection. In: Mayhall CG, editor. Hospital Epidemiology and Infection Control. 2nd ed. Philadelphia, PA: Lippincott Williams \& Wilkins (1999).

5. Lowbury EJL, Lilly HA. Disinfection of the hands of surgeons and nurses. $\mathrm{Br}$ Med J. (1960) 1:5184. doi: 10.1136/bmj.1.5184.1445

6. Widmer AF. Replace hand washing with use of a waterless alcohol hand rub? Clin Infect Dis. (2000) 31:136-43. doi: 10.1086/313888

7. WHO Guidelines on Hand Hygiene in Health Care: First Global Patient Safety Challenge Clean Care Is Safer Care. Geneva: World Health Organization (2009).

8. Global Guidelines for the Prevention of Surgical Site Infection. Geneva: World Health Organization (2016).

9. Rotter, Manfred. New European standard (EN 12791) for testing the efficacy of surgical hand antiseptics. In: Round Table Series - Royal Society of Medicine (2007). p. 22-25.

10. Recommended practices for surgical hand antisepsis/hand scrubs. Assoc Operat Room Nurses J. (2004) 79:416-31. doi: 10.1016/S0001-2092(06)60619-4

11. Babb JR, Davies JG, Ayliffe GAJ. A test procedure for evaluating surgical hand disinfection. J Hospital Infect. (1991) 18:41-49. doi: 10.1016/0195-6701(91)90262-7

12. Hobson DW, Woller W, Anderson L, Guthery E. Development and evaluation of a new alcohol-based surgical hand scrub formulation with persistent antimicrobial characteristics and brushless application. Am J Infect Control. (1998) 26:507-12. doi: 10.1016/S0196-6553(98)70024-0

13. Rotter ML. European norms in hand hygiene. J Hospital Infect. (2004) 56(Suppl. 2):S6-9. doi: 10.1016/j.jhin.2003.12.024

14. Heeg P, Ulmer R, Schwenzer N. Verbessern Haendewaschen und Verwendung der Handbuerste das Ergebnis der Chirurgischen Haendedesinfektion? [Does handwashing and use of brush improve the result of surgical hand disinfection?]. Hyg Med. (1988) 13:270-2.

15. Rotter ML, Koller W. Effekt der sequentiellen Anwendung von Chlorhexidinseife und einer alkoholischen CHX-Praeparation versus Flüssigseife und einer solchen Praeparation bei der Chirurgischen Haendedesinfektion. [Effect of sequential use of chlorhexidine soap and an alcoholic-chlorhexidine preparation versus liquid soap and alcoholicchlorhexidine preparation on surgical hand disinfection]. Hyg Med. (1990) 15:404-37.

16. Bettin K, Clabots C, Mathie P, Willard K, Gerding DN. Effectiveness of liquid soap vs. chlorhexidine gluconate for the removal of Clostridium difficile from bare hands and gloved hands. Infect Control Hospital Epidemiol. (1994) 15:697-702. doi: 10.2307/30148335

17. Koski JM, Helle M. Ultrasound guided synovial biopsy using portal and forceps. Ann Rheum Dis. (2005) 64: 926-9. doi: 10.1136/ard.2004.027409 needle path toward the synovial thickening prevents many problems.

Finally, intra-articular glucocorticoid injections can be safely performed at the end of the procedure if clinically necessary.

\section{AUTHOR CONTRIBUTIONS}

All authors listed have made a substantial, direct and intellectual contribution to the work, and approved it for publication.

18. Lazarou I, D’Agostino MA, Naredo E, Humby F, Filer A, Kelly SG. Ultrasound-guided synovial biopsy: a systematic review according to the OMERACT filter and recommendations for minimal reporting standards in clinical studies. Rheumatology (2015) 54:1867-75. doi: 10.1093/rheumatology/kev128

19. Fleischer W, Reimer K. Povidone-iodine in antisepsis - State of the art. Dermatology (1997) 195(Suppl. 2):3-9. doi: 10.1159/000246022

20. Gulihar A, Robati S, Twaij H, Salih A, Taylor GJ. Articular cartilage and local anaesthetic: a systematic review of the current literature. J Orthop. (2015) 12(Suppl 2):S200-10. doi: 10.1016/j.jor.2015.10.005

21. Kreuz PC, Steinwachs M, Angele P. Single-dose local anesthetics exhibit a type-, dose-, and time-dependent chondrotoxic effect on chondrocytes and cartilage: a systematic review of the current literature. Knee Surg Sports Traumatol Arthrosc. (2018) 26:819-30. doi: 10.1007/s00167-017-4470-5

22. Di Salvo A, Chiaradia E, della Rocca G, Mancini F, Galarini R, Giusepponi D. Intra-articular administration of lidocaine plus adrenaline in dogs: Pharmacokinetic profile and evaluation of toxicity in vivo and in vitro. Vet J. (2016) 208:70-5. doi: 10.1016/j.tvjl.2015.09.004

23. Gomoll AH, Kang RW, Williams JM, Bach BR, Cole BJ. Chondrolysis after continuous intra-articular bupivacaine infusion: an experimental model investigating chondrotoxicity in the rabbit shoulder. Arthroscopy (2006) 22:813-9. doi: 10.1016/j.arthro.2006.06.006

24. Johnson SM, Saint John BE, Dine AP. Local anesthetics as antimicrobial agents: a review. Surg Infect. (2008) 9:205-13. doi: 10.1089/sur.2007.036

25. Parr AM, Zoutman DE, Davidson JS. Antimicrobial activity of lidocaine against bacteria associated with nosocomial wound infection. Ann Plast Surg. (1999) 43:239-45. doi: 10.1097/00000637-19990900000003

26. Kelly S, Humby F, Filer A, Ng N, Di Cicco M, Hands RE, et al. Ultrasound-guided synovial biopsy: a safe, well-tolerated and reliable technique for obtaining high-quality synovial tissue from both large and small joints in early arthritis patients. Ann Rheumat Dis. (2015) 74:611-7. doi: 10.1136/annrheumdis-2013-204603

27. Bruens ML, van der Zaag-Loonen HJ, Steenstra F, Stemerding AM, Wijngaarden S. Septic arthritis after intra-articular injection is rare: does the Taskforce Infection Prevention use a sledgehammer to crack a nut? Ned Tijdschr Geneeskd. (2016) 160:D789.

28. Just SA, Humby F, Lindegaard H, Meric de Bellefon L, Durez P, Vieira-Sousa E, et al. Patient- reported outcomes and safety in patients undergoing synovial biopsy: comparison of ultrasound-guided needle biopsy, ultrasound-guided portal and forceps and arthroscopic-guided synovial biopsy techniques in five centers across Europe. RMD Open (2018) 4:e000799. doi: 10.1136/rmdopen-2018-000799

Conflict of Interest Statement: The authors declare that the research was conducted in the absence of any commercial or financial relationships that could be construed as a potential conflict of interest.

Copyright (C) 2019 Meric De Bellefon and Lazarou. This is an open-access article distributed under the terms of the Creative Commons Attribution License (CC BY). The use, distribution or reproduction in other forums is permitted, provided the original author(s) and the copyright owner(s) are credited and that the original publication in this journal is cited, in accordance with accepted academic practice. No use, distribution or reproduction is permitted which does not comply with these terms. 